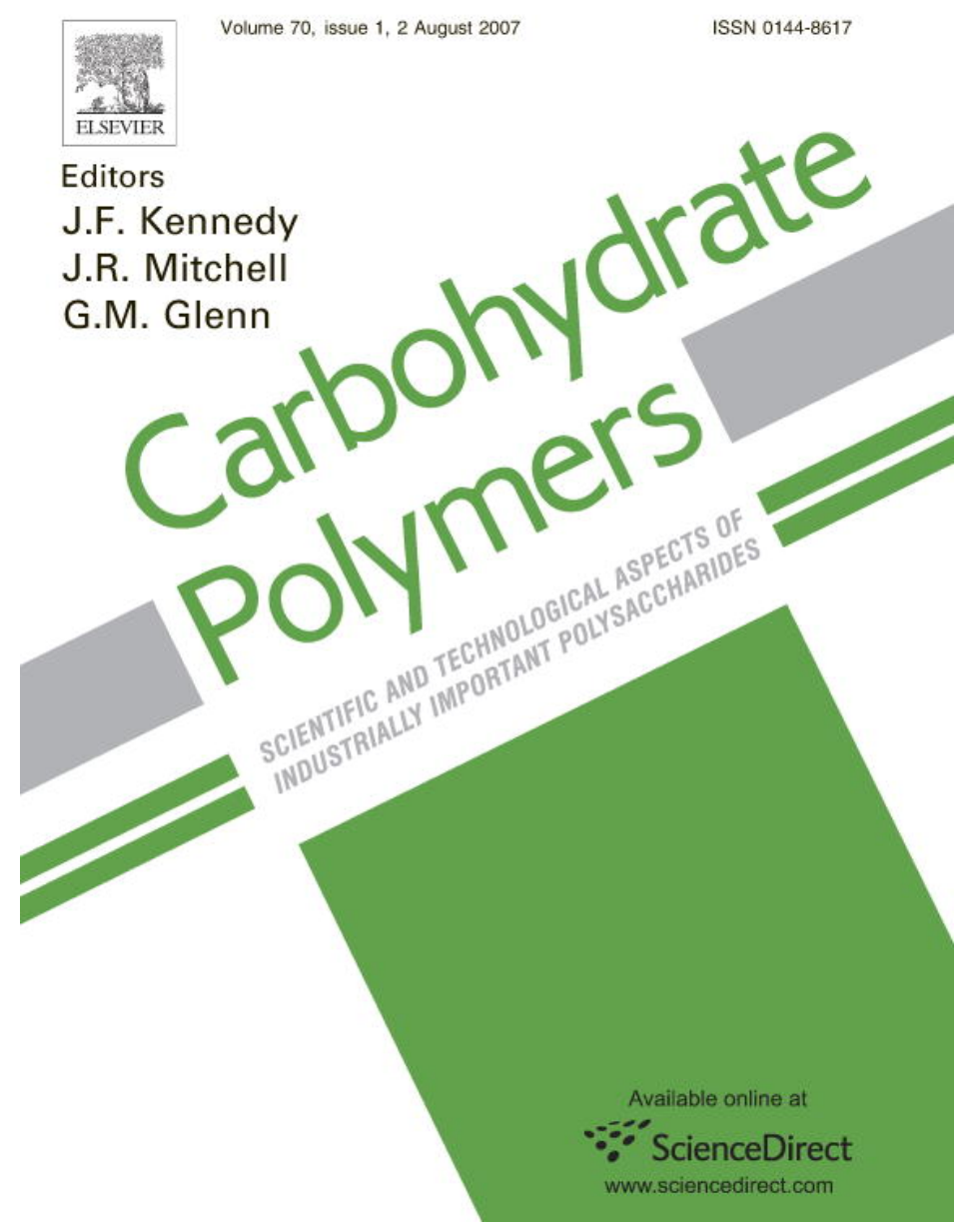

This article was published in an Elsevier journal. The attached copy

is furnished to the author for non-commercial research and education use, including for instruction at the author's institution, sharing with colleagues and providing to institution administration.

Other uses, including reproduction and distribution, or selling or licensing copies, or posting to personal, institutional or third party websites are prohibited.

In most cases authors are permitted to post their version of the article (e.g. in Word or Tex form) to their personal website or institutional repository. Authors requiring further information regarding Elsevier's archiving and manuscript policies are encouraged to visit: 


\title{
Morphology and miscibility of chitosan/soy protein blended membranes
}

\author{
S.S. Silva ${ }^{\text {a,b,* }}$, B.J. Goodfellow ${ }^{c}$, J. Benesch ${ }^{\text {a,b }}$, J. Rocha ${ }^{\text {c }}$, J.F. Mano ${ }^{\text {a,b }}$, R.L. Reis ${ }^{a, b}$ \\ a $3 B$ 's Research Group - Biomaterials, Biodegradables and Biomimetics, Department of Polymer Engineering, University of Minho, \\ Campus de Gualtar, 4710-057 Braga, Portugal \\ ${ }^{\mathrm{b}}$ IBB - Institute for Biotechnology and Bioengineering, PT Government Associated Laboratory, Braga, Portugal \\ ${ }^{\mathrm{c}}$ Department of Chemistry, CICECO, University of Aveiro, Campus de Santiago, 3810-193 Aveiro, Portugal
}

Received 7 December 2006; received in revised form 14 February 2007; accepted 23 February 2007

Available online 28 February 2007

\begin{abstract}
A physico-chemical characterization of blended membranes composed by chitosan and soy protein has been carried out in order to probe the interactions that allow membranes to be formed from these biopolymer mixtures. These membranes are developed aiming at applications in wound healing and skin tissue engineering scaffolding. The structural features of chitosan/soy blended membranes were investigated by means of solid state carbon nuclear magnetic resonance (NMR), infrared spectroscopy (FTIR), contact angle, and atomic force microscopy. FTIR investigations suggested that chitosan and soy may have participated in a specific intermolecular interaction. The proton spin-lattice relaxation experiments in the rotating frame on blended membranes indicated that independently of the preparation conditions, the blend components are not completely miscible possibly due to a weak polymer-protein interaction. It was also shown that the blended systems showed a rougher surface morphology which was dependent of soy content in the blend system. (c) 2007 Elsevier Ltd. All rights reserved.
\end{abstract}

Keywords: Chitosan; Soy protein; Blend membrane; Miscibility; Interactions; Time relaxation

\section{Introduction}

Over the last decade, membranes obtained by combining proteins (e.g. soy protein, collagen, and gelatin) with a natural polymer (e.g. cellulose, chitosan) have been developed in an attempt to supply the high demand for new materials for skin repair as wound dressings in the treatment of wounds caused by burns (Azad, Sermsintham, Chandrkrachang, \& Stevens, 2004; Jeschke, Sandmann, Schubert, \& Klein, 2005; Silva, Santos, Coutinho, Mano, \& Reis, 2005). The presence of a protein in a polysaccharide-protein blend may improve the cell adhesion response of the resultant material due the presence of more protein-binding sites

\footnotetext{
* Corresponding author. Address: 3B's Research Group - Biomaterials, Biodegradables and Biomimetics, Department of Polymer Engineering, University of Minho, Campus de Gualtar, 4710-057 Braga, Portugal. Tel.: +351 253604 781; fax: +351 253604498 .

E-mail address: simonesilva@dep.uminho.pt (S.S. Silva).

URL: www.3bs.uminho.pt
}

(Silva et al., 2005). However, mixtures of protein and polysaccharide are often unstable, which leads to separation into two phases (Bourriot, Garnier, \& Doublier, 1999; Tolstoguzov, 2000). If the biopolymers are incompatible, i.e. they repel each other, thermodynamic phase separation occurs, also called segregation or depletion interaction. After phase separation, the mixture exhibits two phases: one rich in protein and the other rich in polysaccharide (de Kruif \& Tuinier, 2001; Tolstoguzov, 2000). Bourriot et al. (1999) observed that the phase separation occurred in different casein-carrageenan systems at $50{ }^{\circ} \mathrm{C}$. The phase separation leads to the formation of a casein-rich phase and a $\mathrm{k}$-carrageenan-rich phase. Some researchers support the evidence of interactions between protein and polysaccharides at fluid interfaces in conditions of limited thermodynamic compatibility between the protein and polysaccharide, i.e. above the protein isoelectric point in the diluted concentration region (Baeza, Carrera, Pilosof, \& Rodriguez, 2004).

The production and successful use of materials obtained from mixtures of protein-polysaccharide require that their 
properties, including intermolecular interactions, miscibility, morphology, and compatibility are known.

Soy protein, the major component of the soybean, is biodegradable, environmentally friendly, and readily available from an abundant renewable resource. It had been considered an interesting starting material for the development of new materials ad devices for biotechnological and biomedical utilization (Silva et al., 2005; Vaz, Graaf, Reis, \& Cunha, 2002; Vaz et al., 2005). However, soy protein films are very brittle and hydroscopic (Rhim, Gennadios, Handa, Weller, \& Hanna, 2000). To overcome this limitation, soy protein has been blended with other proteins (Silva, Vaz, Coutinho, Cunha, \& Reis, 2003) or polysaccharides (Silva, Elvira, Mano, San Roman, \& Reis, 2004; Silva et al., 2005; Tang, Du, Zheng, \& Fan, 2003) and this has been shown to improve some of the resultant properties, such as mechanical and water vapour barrier of protein films.

Chitosan-based materials have been used for a wide range of biomedical applications (Mi et al., 2001; Suh \& Matthew, 2000; Silva et al., 2004; Silva et al., 2005; Tuzlakoglu, Alves, Mano, \& Reis, 2004). Chemically, chitosan is a natural polymer, which contains $\beta-1-4$ linked 2-amino-2-deoxy-D-glucopyranose repeat units and is readily obtained by the $N$-deacetylation of chitin, a naturally abundant polysaccharide (Azad et al., 2004; $\mathrm{Mi}$ et al., 2001). This polymer is soluble in low $\mathrm{pH}$ $(\mathrm{pH}<6.5)$, and insoluble in a neutral and alkaline medium. In an aqueous acid medium, the amine group of chitosan is protonated, the polymer behaves like cationic polyelectrolyte (Mi et al., 2001). Previous studies (Hattori, Numamoto, Kobayashi, \& Takahashi, 2000; Silva, Lima, Pinheiro, Goés, \& Figueiro, 2001; Silva et al., 2004; Silva et al., 2005) have shown that chitosan can interact with proteins to form insoluble complexes and biofilms. For example, the presence of chitosan has been shown to increase the thermal stability of collagen films, probably due to an increase in the denaturation temperature of collagen-chitosan films over that of collagen alone (Silva et al., 2001). It has also been shown that chitosan will form covalent complexes with $\beta$-lactoglobulin (Hattori et al., 2000) through a Maillard type reaction. The results of a previous study (Silva et al., 2005) demonstrate that the combination of chitosan with a colloidal suspension formed from soy protein, in a form of blended membranes exhibit different degradation patterns and improved cellular adhesion with respect to pure chitosan. The results indicate that the characteristics of this blend system are dependent on the composition of the blend, as well as the interaction between chitosan and the soy protein. However, the way in which chitosan and soy interact has not been fully studied. Therefore the aim of this work is to analyze the miscibility and the morphological aspects of chitosan/soy blended membranes, using measurements of proton spin-lattice relaxation times by solid state carbon nuclear magnetic resonance $\left({ }^{13} \mathrm{C} \quad \mathrm{CP} / \mathrm{MAS} \mathrm{NMR}\right)$, Fourier transform infrared spectroscopy (FTIR), contact angle measurements, atomic force microscopy (AFM), and scanning electron microscopy (SEM).

\section{Experimental}

\subsection{Materials and samples preparation}

Chitosan (CHT, Sigma) with ca. 85\% deacetylation was used. Soy protein isolate was provided by Loders Crocklaan (The Netherlands). All other reagents were analytical grade and used as received.

Chitosan/soy protein blended membranes (CS) (average thickness from 40 to $84 \mu \mathrm{m}$ ) were prepared by solvent casting, as described previously (Silva et al., 2005). Briefly, chitosan flakes were dissolved in an aqueous acetic acid $2 \%(\mathrm{v} / \mathrm{v})$ solution at a concentration of $1 \%(\mathrm{w} / \mathrm{v})$. A soy suspension, $1 \%(\mathrm{w} / \mathrm{v})$, was prepared by slowly suspending the soy protein powder, under constant stirring, in distilled water with glycerol (water/glycerol $(10 \%$ w/v)). After adjusting the $\mathrm{pH}$ to $8.0 \pm 0.3$ with $1 \mathrm{M}$ sodium hydroxide, the dispersion was heated in a water bath at $50{ }^{\circ} \mathrm{C}$ for $30 \mathrm{~min}$. The two solutions were then mixed at different ratios, namely CS75, CS50, and CS25 corresponding to $75 / 25,50 / 50$, and 25/75 w/w (chitosan/soy). After homogenization, the solutions were cast into Petri dishes and dried at room temperature.

\subsection{Fourier transform infrared with attenuated total reflection (FTIR-ATR)}

Surface changes on membranes were assessed by FTIR-ATR spectroscopy (Unican Mattson 7000 FTIR spectrometer). All spectra were an average of 64 scans at a resolution of $4 \mathrm{~cm}^{-1}$.

\subsection{Solid state nuclear magnetic resonance (NMR)}

The solid state NMR spectra were recorded on Bruker DRX spectrometers operating at a ${ }^{1} \mathrm{H}$ frequencies of 400 and $500 \mathrm{MHz}$. Proton spin-lattice relaxation time $\left(T_{1}^{\mathrm{H}}\right)$ values were determined using a ${ }^{1} \mathrm{H}_{-}-{ }^{13} \mathrm{C}$ cross-polarization (CP) inversion recovery sequence (Zhong \& MI, 1999) and by fitting the ${ }^{13} \mathrm{C}$ peak intensities to a single exponential.

\subsection{Contact angle measurements}

The surface properties of the membranes were assessed by means of static contact angle $(\theta)$ measurements using the sessile drop method with ultra-pure distilled water (polar) and diiodomethane (non-polar) (OCA equipment, Germany and SCA-20 software). Six measurements were carried out for each sample. The presented data were calculated using the final averaged values. The polarity of the surface as well as the surface tension was calculated using the Owens-Wendt equation. 


\subsection{Scanning electron microscopy}

SEM images of samples coated with gold were obtained at $10 \mathrm{kV}$ on a Leica Cambridge S-360 microscope equipped with a LINK eXLII X-ray energy dispersion spectrometer for silicon microanalysis.

\subsection{Atomic force microscopy}

The samples were measured on at least three spots using TappingMode ${ }^{\mathrm{TM}}$ with a MultiMode connected to a NanoScope, both supplied from Veeco, USA, with non-contacting silicon nanoprobes (ca. $300 \mathrm{kHz}$, setpoint 2-3 V) from Nanosensors, Switzerland. All images $(10 \mu \mathrm{m}$ wide) were fitted to a plane using the 3rd degree flatten procedure included in the NanoScope software version 4.43r8. The surface roughness was calculated as $\mathrm{Sq}$ (root mean square from average flat surface) and Sa (average absolute distance from average flat surface). The values are presented as mean (standard deviation).

\section{Results and discussion}

Blend solutions of chitosan and soy protein prepared at different ratios appeared to be homogeneous at a macroscopic level. A mixed biopolymer system is thermodynamically unstable, and a phase separation may not be observed on the experimental time scale because of kinetic energy barriers associated with the restricted movement of molecules through biopolymer networks (Bryant \& McClements, 2000).

After casting, the as-prepared membranes presented a yellowish color. In addition, it was found that the blended membranes became brittle with increasing soy protein content. Cho et al. (Cho \& Rhee, 2002) reported that films formed from purely protein tend to be brittle, and plasticizers should be added to overcome the brittleness of films. As expected, the SEM images of the CS blended membranes showed a rougher surface morphology than the pure chitosan membrane (Fig. 1). Additionally, the AFM images (Fig. 2) show that the morphology of the blended
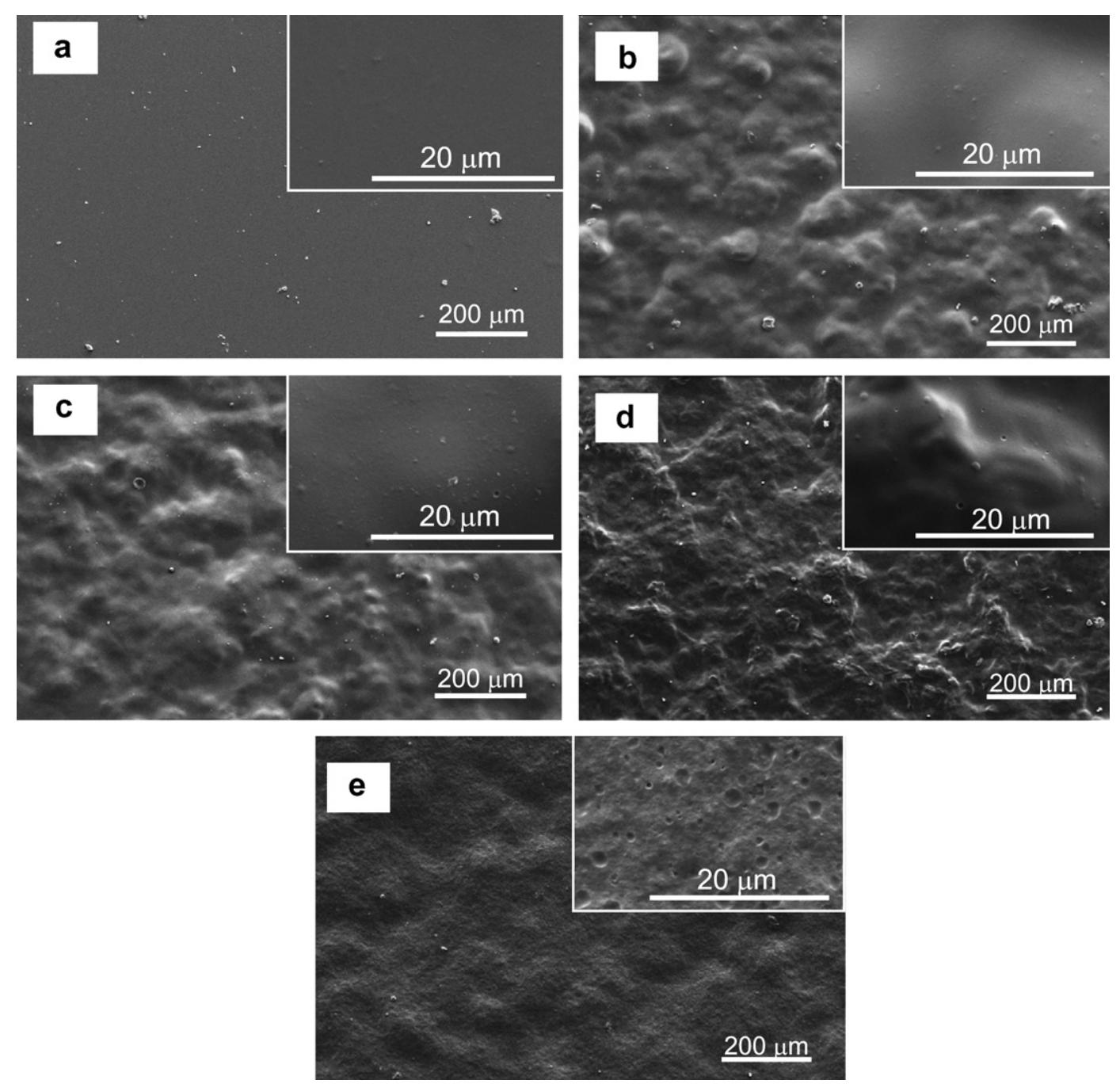

Fig. 1. SEM micrographs of chitosan membrane (a), soy protein membrane (b), CS75 (c), CS50 (d), and CS25 (e). The inset pictures present a higher magnification of the membranes surfaces. (CS75, CS50, and CS25 corresponding to 75/25, 50/50, and 25/75 wt \% chitosan/soy). 

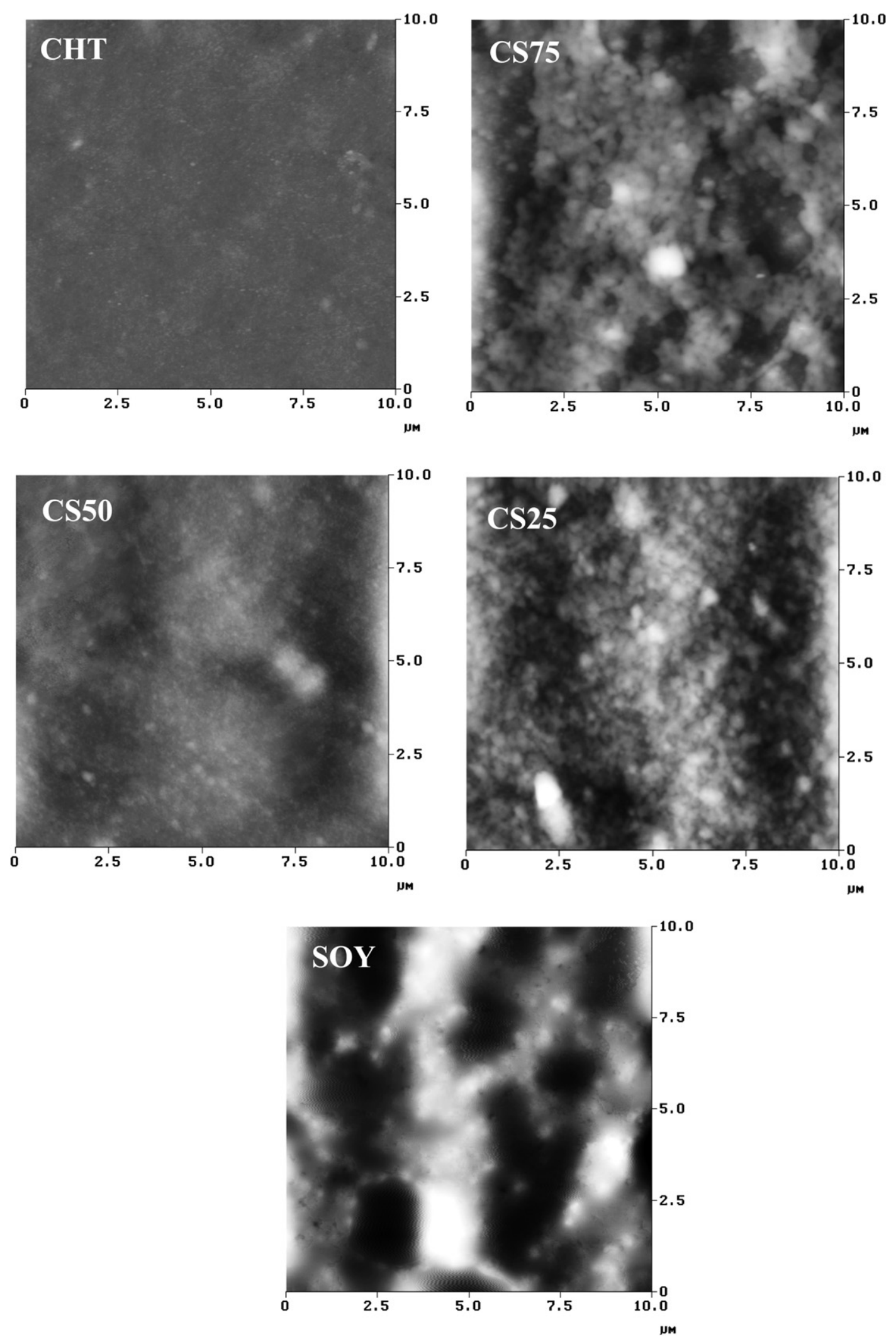

Fig. 2. AFM images of membranes: chitosan membranes (CHT), CS75, CS50, CS25 and soy protein membrane. (CS75, CS50, and CS25 corresponding to $75 / 25,50 / 50$, and $25 / 75 \mathrm{wt} \%$ chitosan/soy.)

membranes appear as a dispersion of one polymer in the matrix of the other, as it is commonly found in heterogeneous blends (Koning, van Duin, Pagnoulle, \& Jerome,
1998). From AFM measurements it was noted that the surface roughness increased with increasing soy protein content from $11.8 \pm 2.8 \mathrm{~nm}(\mathrm{CS} 75)$ to $18.8 \pm 6.4 \mathrm{~nm}(\mathrm{CS} 25)$, 
Table 1

Contact angles $(\theta)$ and surface energy $(\gamma)$ of chitosan, soy protein, and their blended membranes

\begin{tabular}{lrlrr}
\hline Membrane & $\theta_{\text {Water }}\left({ }^{\circ}\right)$ & $\theta_{\text {Diiodomethane }}\left({ }^{\circ}\right)$ & $\gamma_{\mathrm{d}}\left(\mathrm{mN} \mathrm{m}^{-1}\right)$ & $\gamma_{\mathrm{p}}\left(\mathrm{mN} \mathrm{m}^{-1}\right)$ \\
\hline CHT & $103.1 \pm 3.2$ & $61.3 \pm 0.5$ & $27.4 \pm 0.1$ & $0.4 \pm 0.1$ \\
CS75 & $92.4 \pm 2.8$ & $61.7 \pm 2.4$ & $24.7 \pm 0.1$ & $2.1 \pm 0.0$ \\
CS50 & $88.2 \pm 2.0$ & $55.3 \pm 2.4$ & $29.2 \pm 0.1$ & $26.8 \pm 0.1$ \\
CS25 & $75.2 \pm 3.8$ & $53.1 \pm 1.8$ & $26.1 \pm 0.1$ & $31.2 \pm 0.1$ \\
SOY & $67.6 \pm 4.2$ & $63.5 \pm 1.9$ & $19.4 \pm 0.1$ & $3.7 \pm 0.06$ \\
\hline
\end{tabular}

in comparison to the roughness of soy protein $(35.5 \pm 4.5 \mathrm{~nm})$ and chitosan $(1.8 \pm 0.9 \mathrm{~nm})$ membrane alone, in accordance with the SEM results. Soy $\left({ }^{* *}\right)$ and chitosan $\left(^{*}\right)$ alone were significantly different from all other samples. In contrast, considering experimental error, only the CS25-CS75 pair shows a significant difference.

The measured contact angles and the calculated surface energy of the prepared membranes are summarized in Table 1. It can be seen from this data that the soy protein films are more hydrophilic than the chitosan membranes. As expected, the blending of chitosan with the soy protein resulted in a decrease in the values of the water contact angles of the blended membranes with an increase in the soy protein ratio. The surface energy $(\gamma)$ of CS blended membranes increases in comparison to pure chitosan, as a result of the mixing of chitosan and soy protein in these blended system. However, no significant changes were seen for the non-polar and polar components of the surface energy.

The FTIR-ATR spectra of chitosan, soy protein, and blended membranes are shown in Fig. 3. The ATR analysis

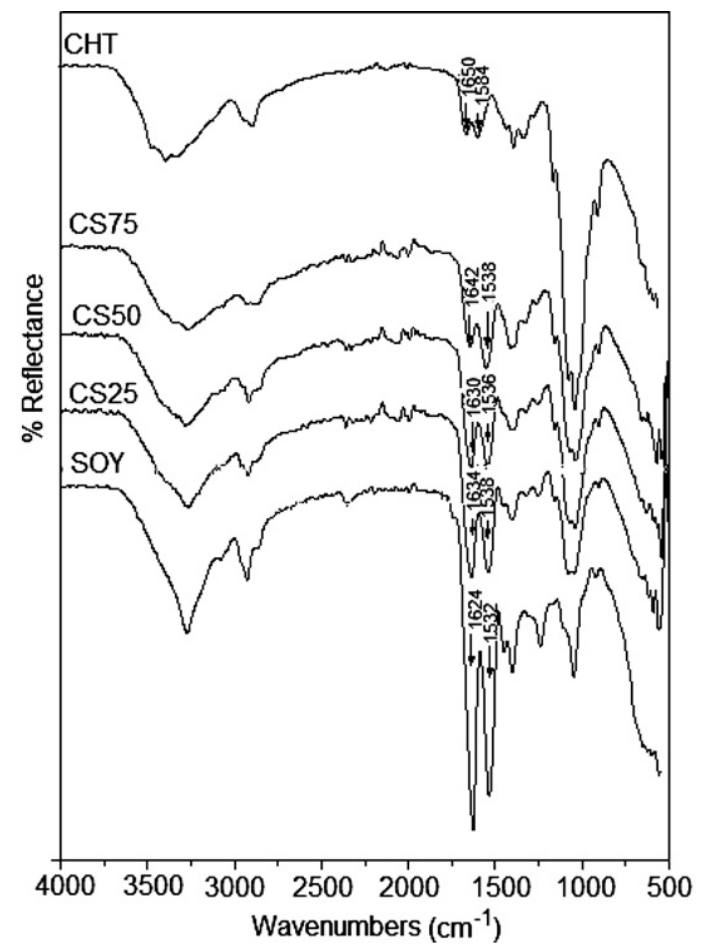

Fig. 3. FTIR-ATR of the CS blended membranes. (CS75, CS50, and CS25 corresponding to $75 / 25,50 / 50$, and $25 / 75 \mathrm{wt} \%$ chitosan/soy.) of membranes was based on the identification of bands related to the functional groups present in chitosan and soybean, among others (Pawlak \& Mucha, 2003; Subirade, Kelly, Gueguen, \& Pezolet, 1998). The main characteristics absorption bands of chitosan appear at $1650 \mathrm{~cm}^{-1}(\mathrm{C}=\mathrm{O}$ stretching), $1584 \mathrm{~cm}^{-1}$ (-NH angular deformation), and $1150-1040 \mathrm{~cm}^{-1}$ (-C-O-C- in glycosidic linkage) (Pawlak $\&$ Mucha, 2003). The soy protein spectrum showed an amide I band at $1632 \mathrm{~cm}^{-1}$ and a amide II band at $1536 \mathrm{~cm}^{-1}$ (Subirade et al., 1998). The amide I can be composed of several overlapping components due to various protein segments with different secondary structures (Subirade et al., 1998). As can be seen in spectra of the blended membranes, the characteristic absorptions bands of both chitosan and soy protein appears in proportion to the ratio between the components of the blend. As a result, the absorbance of $\mathrm{NH}$ and $\mathrm{CO}$ deformation bands in the range $1580-1490$ and $1700-1630 \mathrm{~cm}^{-1}$, respectively, increase with the increase in soy content of the blend. A small displacement of these bands to lower wave-numbers ( $\mathrm{NH}$ from 1584 to $1536 \mathrm{~cm}^{-1}$ and CO from 1650 to $1630 \mathrm{~cm}^{-1}$ ) with respect to pure chitosan was also noted. These shifts suggest that there may be a specific chemical interaction occurring between chitosan and soy.

Fig. 4 shows the ${ }^{13} \mathrm{C} \mathrm{CP} / \mathrm{MAS}$ NMR spectra of chitosan, soy protein and their blends. Comparing the ${ }^{13} \mathrm{C}$ CP/MAS NMR spectra of chitosan and soy protein it was possible to identify a characteristic ${ }^{13} \mathrm{C}$ peak for the polysaccharide at $104 \mathrm{ppm}$ (C1 ring carbon) and for the protein at $172 \mathrm{ppm}$ (backbone carbonyl group) (Cervera et al., 2004; Mizuno, Mitsuiki, Motoki, Ebisawa, \& Suzuki, 2000). These resonances are distinct from one another and can be used to probe the components of the membrane. Chitosan has a very weak peak at around 175 ppm from the acetyl group carbonyl carbon which does not interfere with the soy carbonyl resonance (Fig. $4 \mathrm{c}$ ). The ${ }^{13} \mathrm{C}$ peak at $104 \mathrm{ppm}$ in the soy spectra (Fig. 4b) is a spinning side band. To examine the miscibility of the components of chitosan/ soy protein blended membranes at length scales of the order of $\mathrm{nm}$, the proton spin-lattice relaxation times in the rotating frame, $T_{1 \rho}\left({ }^{1} \mathrm{H}\right)$, were measured. The results are summarized in Table 2. If there is intimate mixing of the polysaccharide and protein molecules the $T_{1 \rho}\left({ }^{1} \mathrm{H}\right)$ values will be equal. If, however, the polysaccharide/protein zones are larger than approximately $20 \mathrm{~nm}$ (i.e. physically separated) then their relaxation times will differ. It is clear that the CS50 $T_{1}\left({ }^{1} \mathrm{H}\right)$ values for the protein and polysaccharide that are clearly different. Therefore it appears 

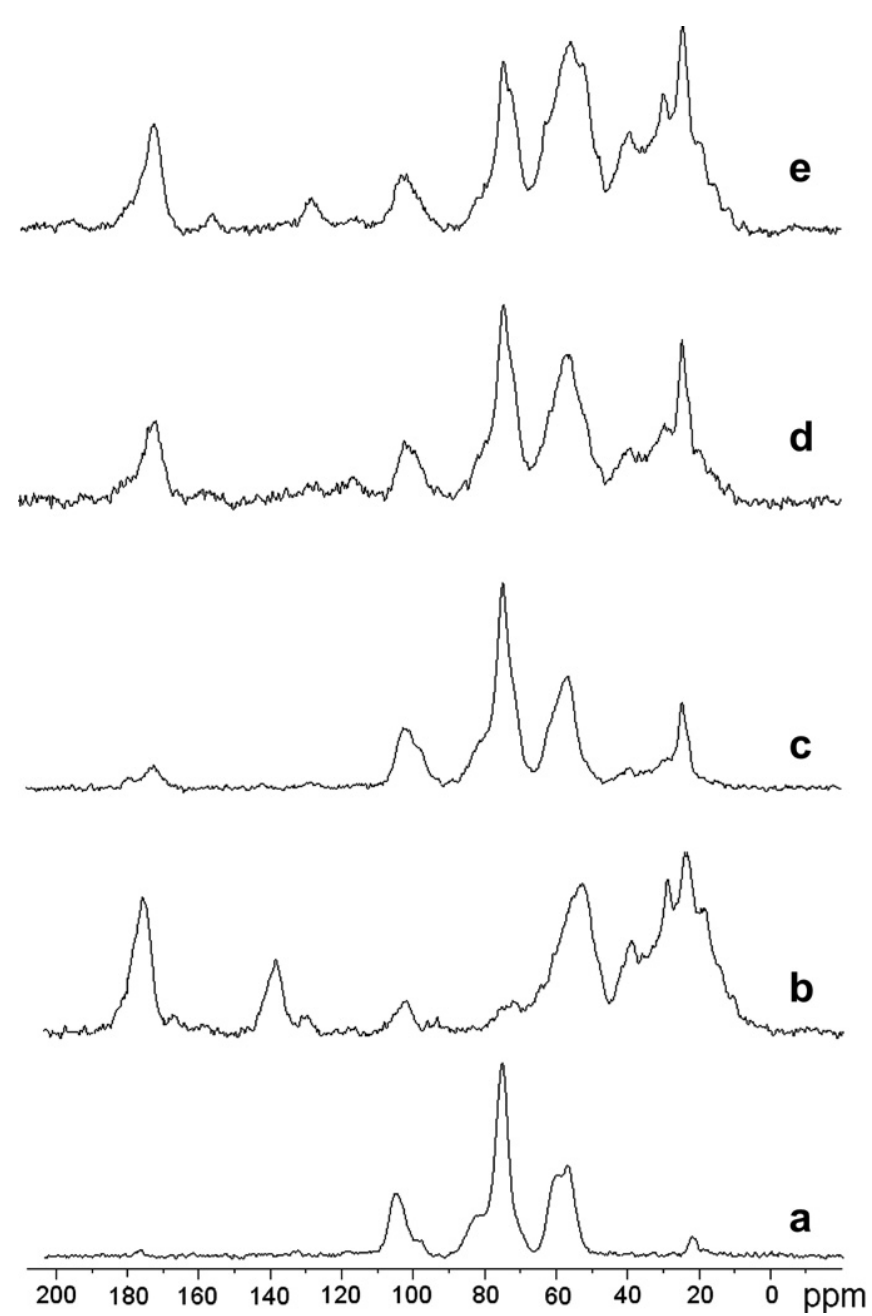

Fig. 4. ${ }^{13} \mathrm{C}$ NMR spectra of the chitosan (a), soy protein (b), CS75 (c), CS50 (d), and CS25 (e). (CS75, CS50, and CS25 corresponding to 75/25, $50 / 50$, and $25 / 75 \mathrm{wt}^{\%} \%$ chitosan/soy.)

Table 2

$T_{1 \rho}\left({ }^{1} \mathrm{H}\right)[\mathrm{ms}]$ values measured for selected resonances to chitosan, soy protein, and their blend membranes

\begin{tabular}{llll}
\hline Sample & Peak 172-180 $[\mathrm{ms}]$ & Peak 104 [ms] & \\
Chitosan & - & $697.6 \pm 2.7$ & \\
Soy protein & $602.2 \pm 14.7$ & - & Increasing chitosan amount \\
CS75 & $639.8 \pm 4.2$ & $619.4 \pm 8.0$ & \\
CS50 & $627.6 \pm 12.0$ & $392.9 \pm 11.3$ \\
CS25 & $480.0 \pm 12.7$ & $459.6 \pm 15.4$ &
\end{tabular}

that the blend components (at a CS50 ratio), independent of the preparation conditions, are not miscible, possibly as a result of a weak chitosan-protein interaction. However, anomalous behavior has been seen before for water absorption and degradation in CS50 blends (Silva et al., 2005) and these results may be further indication of this phenomenon. Even so, the $T_{1 \rho}\left({ }^{1} \mathrm{H}\right)$ value for the chitosan component is quite different from pure chitosan therefore the dynamic characteristics of chitosan in the CS50 blend must be significantly different.
On the other hand, the CS75 and CS25 samples have $T_{1 \rho}\left({ }^{1} \mathrm{H}\right)$ values for each component that are that same (within experimental error, Table 2). Therefore, it appears that these samples (CS75 and CS25) may have protein and polysaccharide regions that are miscible. However, it is possible that as the percentage of one of the components is low the blends may be immiscible but due to the small physical size of one of the component pools spin diffusion is occurring. The lower $T_{1 \rho}\left({ }^{1} \mathrm{H}\right)$ values of the CS25 blend compared to the CS75 blend, however, imply that the dynamic characteristics for both biopolymers are different in the two blends and that the degree of homogeneity of the CS25 blend is higher than of the CS75. This is most probably due to better interaction of the soy protein-rich phase with the chitosan phase in the CS25 blend.

\section{Conclusions}

A physico-chemical characterization of chitosan/soy protein blends has been carried out in order to probe existing interactions, and the ultra-structure of membranes containing different amounts of the two biopolymers. The use of SEM and AFM indicated that the surface morphology of the membrane blends increased in roughness as the amount of soy protein increased, suggesting increasing heterogeneity. The surface energy of the blended membranes was found to increase when compared to the separate constituents and was highest for the CS25 blend. The source and extent of the interaction between the polysaccharide and protein constituents of the blends was probed using FTIR and NMR. The shift in the $\mathrm{NH}$ and $\mathrm{C}=\mathrm{O}$ bands in the FTIR spectra of the blends compared to pure chitosan suggests a weak interaction is occurring between the two phases. The results from the NMR relaxation studies suggest that there is probably no intimate mixing for CS75 and CS50 although the lower $T_{1 \rho}\left({ }^{1} \mathrm{H}\right)$ values for the CS25 blend suggests that this blend may be the most homogeneous and that the biopolymers have dynamic characteristics different from the isolated components.

\section{Acknowledgements}

S.S. Silva and J. Benesch, thank the Portuguese Foundation for Science and Technology (FCT) for providing PhD and postdoctoral scholarships (SFRH/BD/8658/2002 and SFRH/BPD/20412/2004/0670, respectively) under POCTI program. This work was also partially supported by the European Union funded STREP Project HIPPOCRATES (NMP3-CT-2003-505758).

\section{References}

Azad, A. K., Sermsintham, N., Chandrkrachang, S., \& Stevens, W. F. (2004). Chitosan membrane as a wound-healing dressing: characterization and clinical application. Journal of Biomedical Materials Research Part B-Applied Biomaterials, 69B(2), 216-222. 
Baeza, R., Carrera, S. C., Pilosof, A. M. R., \& Rodriguez, P. J. M. (2004). Interactions of polysaccharides with b-lactoglobulin spread monolayers at the air-water interface. Food Hydrocolloids, 18, 959-966.

Bourriot, S., Garnier, C., \& Doublier, J. L. (1999). Micellar-casein-kcarrageenan mixtures.I. Phase separation and ultrastructure. Carbohydrate Polymers, 40, 145-157.

Bryant, C. M., \& McClements, D. J. (2000). Influence of xanthan gum on physical characteristics of heat-denatured whey protein solutions and gels. Food Hydrocolloids, 14, 383-390.

Cervera, M. F., Heinamaki, J., Rasanen, M., Maunu, S. L., Karjalainen, M., Acosta, O. M. N., et al. (2004). Solid-state characterization of chitosans derived from lobster chitin. Carbohydrate Polymers, 58, 401-408.

Cho, S. Y., \& Rhee, C. (2002). Sorption characteristics of soy protein films and their relation to mechanical properties. Lebensmittel-Wissenschaft und-Technologie, 35, 151-157.

de Kruif, C. G., \& Tuinier, R. (2001). Polysaccharide protein interactions. Food Hydrocolloids, 15(4-6), 555-563.

Hattori, M., Numamoto, K., Kobayashi, K., \& Takahashi, K. (2000). Functional changes in beta-lactoglobulin by conjugation with cationic saccharides. Journal of Agricultural and Food Chemistry, 48, 2050-2056.

Jeschke, M. G., Sandmann, G., Schubert, T., \& Klein, D. (2005). Effect of oxidized regenerated cellulose/collagen matrix on dermal and epidermal healing and growth factors in an acute wound. Wound repair regulation, 13, 324-331.

Koning, C., van Duin, M., Pagnoulle, C., \& Jerome, R. (1998). Strategies for compatibilization of polymer blends. Progress in Polymer Science, 23(4), 707-757.

Mi, F. L., Shyu, S. S., Wu, Y. B., Lee, S. T., Shyong, J. Y., \& Huang, R. N. (2001). Fabrication and characterization of a sponge-like asymmetric chitosan membrane as a wound dressing. Biomaterials, 22(2), $165-173$.

Mizuno, A., Mitsuiki, M., Motoki, M., Ebisawa, K., \& Suzuki, E. (2000). Relationship between the glass transition of soy protein and molecular structure. Journal of Agricultural and Food Chemistry, 48, 3292-3297.

Pawlak, A., \& Mucha, M. (2003). Thermogravimetric and FTIR studies of chitosan blends. Thermochimica Acta, 396, 153-166.

Rhim, J. W., Gennadios, A., Handa, A., Weller, C. L., \& Hanna, M. A. (2000). Solubility, tensile, and color properties of modified soy protein isolate films. Journal of Agricultural and Food Chemistry, 48(10), 4937-4941.

Silva, R. M., Elvira, C., Mano, J. F., San Roman, J., \& Reis, R. L. (2004). Influence of beta-radiation sterilisation in properties of new chitosan/ soybean protein isolate membranes for guided bone regeneration. Journal of Materials Science-Materials in Medicine, 15(4), 523-528.

Silva, C. C., Lima, C. G. A., Pinheiro, A. G., Goés, J. C., \& Figueiro, A. S. B. (2001). On the piezoelectricity of collagen-chitosan films. Physical chemistry physics, 3, 4154-4157.

Silva, S. S., Santos, M. I., Coutinho, O. P., Mano, J. F., \& Reis, R. L. (2005). Physical properties and biocompatibility of chitosan/soy blended membranes. Journal of Materials Science-Materials in Medicine, 16(6), 575-579.

Silva, G. A., Vaz, C. M., Coutinho, O. P., Cunha, A. M., \& Reis, R. L. (2003). In vitro degradation and cytocompatibility evaluation of novel soy and sodium caseinate-based membrane biomaterials. Journal of Materials Science - Materials in Medicine, 14(12), 1055-1066.

Subirade, M., Kelly, I., Gueguen, J., \& Pezolet, M. (1998). Molecular basis of film formation from a soybean protein: comparison between the conformation of glycinin in aqueous solution and in films. International Journal of Biological Macromolecules, 23, 241-249.

Suh, J. K. F., \& Matthew, H. W. T. (2000). Application of chitosan-based polysaccharide biomaterials in cartilage tissue engineering: a review. Biomaterials, 21, 2589-2598.

Tang, R. P., Du, Y. M., Zheng, H., \& Fan, L. H. (2003). Preparation and characterization of soy protein isolate-carboxymethylated konjac glucomannan blend films. Journal of Applied Polymer Science, 88(5), 1095-1099.

Tolstoguzov, V. (2000). Phase behaviour of macromolecular components in biological and food systems. Nahrung-Food, 44(5), 299-308.

Tuzlakoglu, K., Alves, C. M., Mano, J. F., \& Reis, R. L. (2004). Production and characterization of chitosan fibers and 3-D fiber mesh scaffolds for tissue engineering applications. Macromolecular Bioscience, 4, 811-819.

Vaz, C. M., Doeveren, P. F. N. M., Yilmaz, G., Graaf, L. A., Reis, R. L., \& Cunha, A. M. (2005). Processing and characterization of biodegradable soy plastics: effects of crosslinking with glyoxal and thermal treatment. Journal of Applied Polymer Science, 97, 604-610.

Vaz, C. M., Graaf, L. A., Reis, R. L., \& Cunha, A. M. (2002). Soy proteinbased systems for different tissue regeneration applications. Dordrecht: Kluwer Academic Publishers.

Zhong, Z., \& MI, Y. (1999). Thermal characterization and solid-state 13CNMR investigation of blends of poly $(N$-phenyl-2-hydroxytrimethylene amine) and poly( $N$-vinyl pyrrolidone). Journal of Polymer Science Part B: Polymer Physics, 37, 237-245. 